\title{
Diurnal variation in blood 17-hydroxyprogesterone concentrations in untreated congenital adrenal hyperplasia
}

\author{
J SÓLYOM \\ Second Department of Paediatrics, Semmelweis Medical University, Budapest, Hungary
}

SUMMARY Blood spot 17-hydroxyprogesterone concentrations were measured serially over 24 hours in patients with congenital adrenal hyperplasia due to 21-hydroxylase deficiency before they started treatment with glucocorticoids, and the development of diurnal rhythm in pituitary-adrenal activity was studied. Five infants aged 2 to 26 days showed an intradiem variation of 17-hydroxyprogesterone concentrations within the diagnostic range but without a characteristic diurnal pattern. Blood spot 17-hydroxyprogesterone values in a further eight patients aged 3 months to 6.5 years showed a diurnal rhythm, with high concentrations in the morning and a nadir in the evening. The results suggest that a diurnal rhythm in pituitary-adrenal activity may develop as early as the third month of life in those infants with an increased endogenous concentration of adrenocorticotrophic hormone.

The activity of the pituitary-adrenal axis has a characteristic diurnal pattern in adults. ${ }^{1}$ In contrast, conflicting results have been published on the development of diurnal rhythms in the secretion of adrenocorticotrophic hormone and adrenocortical steroids in infancy. ${ }^{2-4}$

Raised morning and low evening concentrations of adrenocorticotrophic and glucocorticoid hormones have been found in patients with congenital adrenal hyperplasia. ${ }^{5}$ Plasma concentrations of 17 alpha-hydroxyprogesterone (17-OHP) are considerably raised in patients with congenital adrenal hyperplasia caused by 21-hydroxylase deficiency. Peak values occur in the morning with low concentrations in the evening in adolescent and adult patients before treatment, ${ }^{6}$ during inadequate treatment, ${ }^{78}$ and after withdrawal of glucocorticoid treatment. $^{9}{ }^{10}$

This paper reports serial measurements of plasma 17-OHP concentrations over a 24 hour period, performed before treatment was started in a group of infants and children with congenital adrenal hyperplasia. The data provide further information on the development and acquisition of diurnal periodicity in pituitary-adrenal activity during early postnatal life.

\section{Materials and methods}

Patients. Thirteen patients with congenital adrenal hyperplasia caused by 21-hydroxylase deficiency were investigated. They had presented with ambiguous external genitalia or salt wasting crises, or both, in the newborn period, or with signs of precocious puberty in older children. At the time of the study there were five infants less than 4 weeks old (all salt losers) and eight children aged 3 months to 6.5 years (one salt loser, seven non-salt losers).

Capillary blood samples were collected onto filter paper every two to four hours over a 24 hour period for serial 17-OHP measurements. The 24 hour sampling protocol was repeated in some cases.

To obtain reference values, the diurnal variation of blood spot 17-OHP concentrations was studied in 20 infants (10 aged 2 days to 6 weeks and 10 aged 3 to 12 months) and 9 children (aged 3 to 12 years) investigated for various disorders but subsequently shown to have no endocrine dysfunction.

To compare serum and blood spot 17-OHP measurements, 64 morning venous samples were collected simultaneously with blood spot samples from 20 patients with congenital adrenal hyperplasia aged 2 days to 15 years before and during glucocorticoid treatment.

\section{7-OHP measurements.}

Blood spot 17-OHP

Standard discs punched out from blood spots on filter paper containing $3 \mu \mathrm{l}$ of serum ${ }^{11}$ were ex- 
tracted with $500 \mu \mathrm{l}$ of phosphate buffered saline followed by $5.0 \mathrm{ml}$ of diethyl ether:ethyl acetate (90:10).

\section{Serum 17-OHP}

Thirty $\mu \mathrm{l}$ of serum plus $200 \mu \mathrm{l}$ of water were extracted with $2.0 \mathrm{ml}$ of the diethyl ether:ethyl acetate mixture.

17-OHP determinations were performed by a non-chromatographic radioimmunoassay. The assay technique has previously been described in detail. ${ }^{12}$

All samples collected from each patient were analysed simultaneously in the same assay. Intraassay coefficients of variation for blood spot 17 OHP were $12 \cdot 2 \%, 11.5 \%$, and $10.9 \%$ at concentrations of $23(n=10), 152(n=10)$, and $670(n=10)$ $\mathrm{nmol} / \mathrm{l}$ respectively. Data on the stability of $17-\mathrm{OHP}$ in blood spots and the sensitivity and interassay precision of the method have been published previously. ${ }^{12} 13$

The daily variation of $17-\mathrm{OHP}$ concentrations in each patient was examined by determining whether the blood spot 17-OHP concentration at a given time of the day differed by more than twice the intra-assay variance $( \pm 23 \%)$ from the mean value (weighted average) observed in the same patient during the 24 hour period.

\section{Results}

There was a close correlation between the 17-OHP measurements, determined by extracting a known amount of serum and using a standard disc with dried blood, over a wide range of serum concentrations (1 to $1870 \mathrm{nmol} / \mathrm{l}$; Fig. 1).

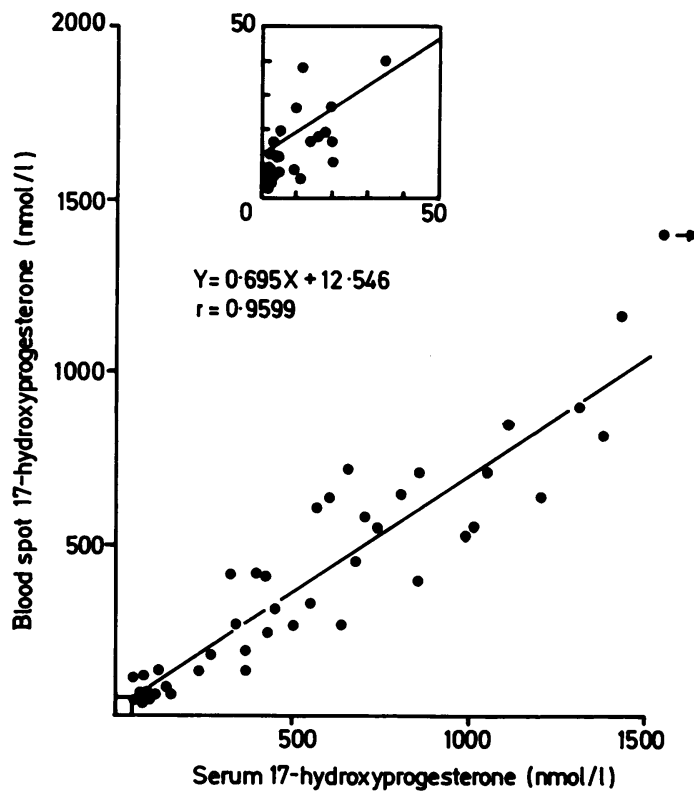

Fig. 1 Linear regression of blood spot

17-hydroxyprogesterone concentrations using the phosphate buffered saline', diethyl ether/ethyl acetate extraction method versus serum 17-hydroxyprogesterone concentrations in blood sample's derived from 64 congenital adrenal hyperplasia patients before and during glucocorticoid treatment. Inse't shows values lower than 50 nmolll.

In control patients sampled during the morning, the range of blood spot 17-OHP concentrations using the phosphate buffered saline extraction method was 20 to $40 \mathrm{nmol} / \mathrm{l}$ in young infants, 8 to 16

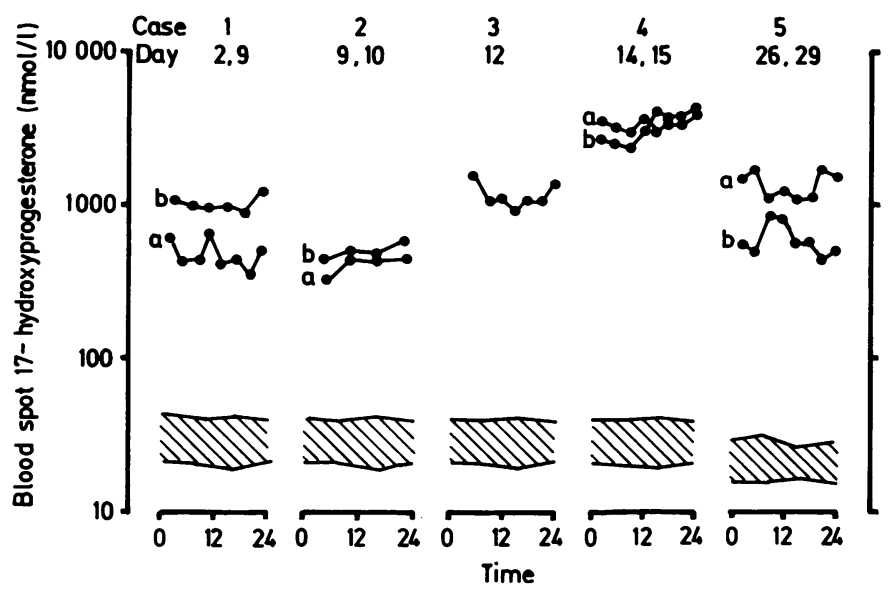

Fig. 2 Diurnal variation in blood spot 17-hydroxyprogesterone values in newborns and infants with untreated congenital adrenal hyperplasia aged from 2 to 26 days

Values obtained during two different 24 hour periods are represented by $a$ and $b$. The shaded areas indicate the range of blood spot 17-hydroxyprogesterone values found in age matched control patients. 


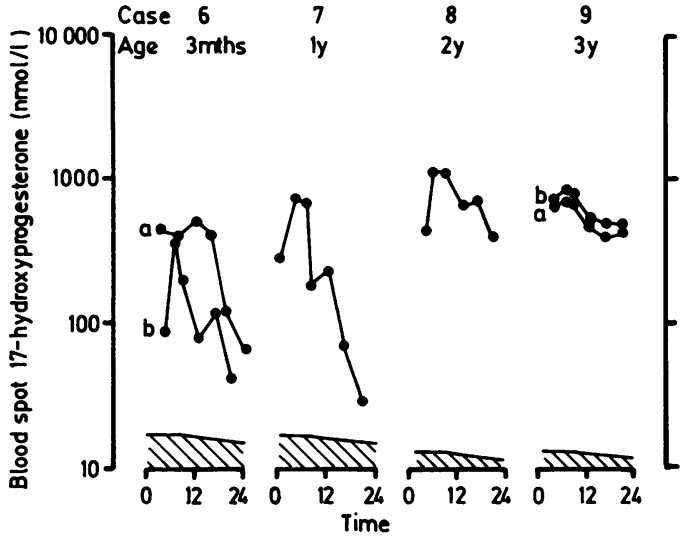

Fig. 3 Diurnal variation of blood spot

17-hydroxyprogesterone values in infants and children with untreated congenital adrenal hyperplasia aged from 3 months to 3 years.

Concentrations obtained during two different $\mathbf{2 4}$ hour periods are represented by $a$ and $b$. The shaded areas indicate the range of 17-hydroxyprogesterone values in age matched controls.

$\mathrm{nmol} / \mathrm{l}$ in older infants, and 5 to $14 \mathrm{nmol} / \mathrm{l}$ in children. Values usually decreased in the evening in patients older than 3 months of age.

The changes in blood spot 17-OHP concentrations during the 24 hour period in untreated patients with congenital adrenal hyperplasia are illustrated in Figs. 2 to 4.

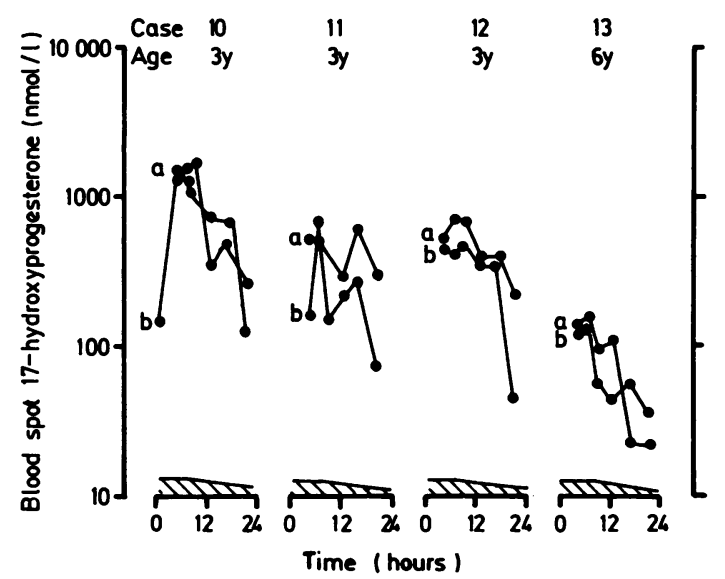

Fig. 4 Diurnal variation of blood spot

17-hydroxyprogesterone values in children with untreated congenital adrenal hyperplasia age from 3 to 6 years.

Concentrations obtained during two different 24 hour periods are represented by $a$ and $b$. The shaded areas represent the range of blood spot 17 hydroxyprogesterone values in age matched controls.
No diurnal rhythm was found in newborns. Intradiem variations in blood spot $17-\mathrm{OHP}$ values greater than $\pm 23 \%$ of the daily mean were observed in four of five patients aged between 2 and 29 days (cases 1, 3, 4, and 5). Morning (6 to 8 am) and evening (9 to $10 \mathrm{pm}) 17-\mathrm{OHP}$ concentrations in these patients varied between 87 and $133 \%$ of the 24 hour mean (average of two values if repeated sampling was performed).

Blood spot 17-OHP values in eight patients aged 3 months to 6.5 years (cases 6 to 13 ) showed a diurnal rhythm, with peaks in the morning and a nadir in the evening. Patients aged more than 3 months showed morning concentrations of blood spot $17-\mathrm{OHP}$ between 142 and $255 \%$ and evening values between 10 and $80 \%$ of the 24 hour mean (Fig. 5).

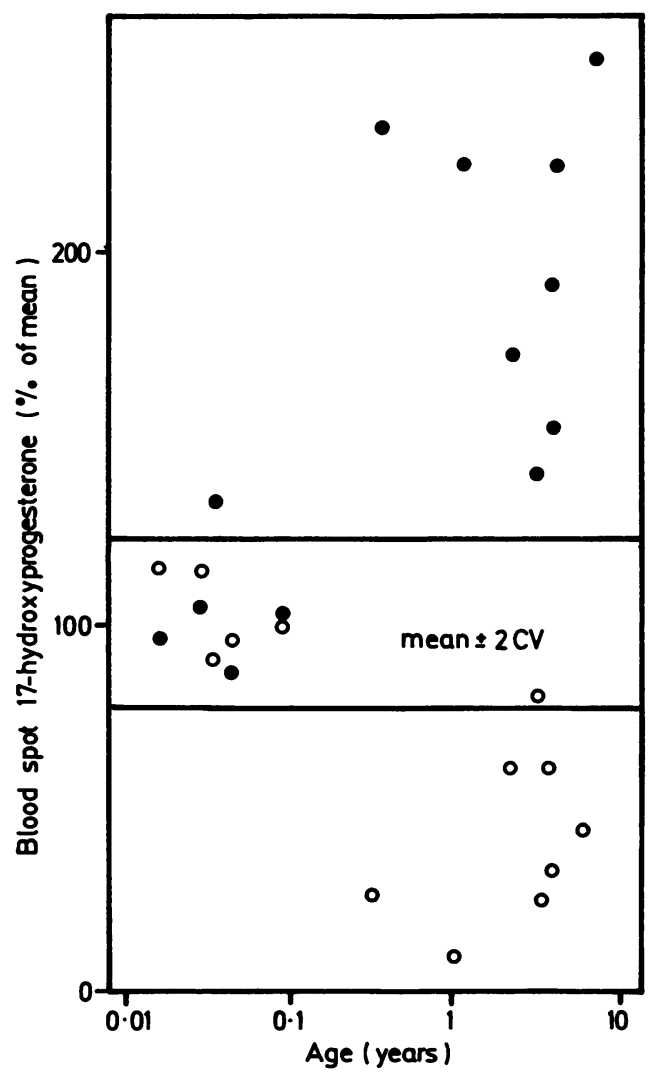

Fig. 5 Morning (O) and evening (O) blood spot 17-hydroxyprogesterone concentrations, expressed as percentages of the 24 hour mean value, in untreated congenital adrenal hyperplasia patients with increasing age.

Means of two values were represented if repeated sampling was performed. Combined intra-assay coefficient of variation (CV) $(11.5 \%)$ is indicated by dashed line. 
There was no significant difference between daily profiles of blood 17-OHP when repeated in the same patient on two different days.

\section{Discussion}

There are no previous studies reporting the diurnal variation in pituitary-adrenal activity in untreated newborns and infants with congenital adrenal hyperplasia. To study the diurnal pattern of 17-OHP concentration in newborns, infants, and children with this disorder a technique using a small amount of capillary blood is required. The blood spot 17-OHP method was first recommended for congenital adrenal hyperplasia screening by Pang et al. ${ }^{14}$ The present study shows a close correlation between serum and blood spot 17-OHP values over a wide range of concentrations. Similar results were obtained by Hubl et al ${ }^{15}$ over a narrower range of concentrations, utilising an enzyme immunoassay procedure.

Blood spot 17-OHP measurements are useful in the early identification and subsequent management of patients with congenital adrenal hyperplasia. ${ }^{11} 12$ The reliability and feasibility of the microfilter paper method have been illustrated by its use in neonatal screening for this disorder. ${ }^{16}{ }^{17}$ In the present study, the method has been applied to document the development of a diurnal rhythm in pituitaryadrenal activity in these patients.

There is a noticeable diurnal rhythm in serum 17-OHP concentrations in treated children with congenital adrenal hyperplasia. ${ }^{18}$ Untreated infants showed no sign of diurnal rhythm in blood 17-OHP concentrations during the first 4 weeks of life. In contrast, two infants aged 3.5 and 12 months and all children had high 17-OHP concentrations in the morning with relatively low values in the evening.

The absence of a diurnal rhythm in serum 17-hydroxycorticosteroids in infants aged 3 to 26 months observed by Franks ${ }^{4}$ may be due to the stressful nature of obtaining blood samples by venepuncture. The presence of stress related illness can also raise 17-OHP values in patients without adrenal disease. ${ }^{19}$ Price $e t a l^{2}$ have recently reported the development of a diurnal rhythm in cortisol concentrations by age 3 months, when this steroid was measured in saliva samples collected relatively stress free.

There are few reports of 24 hour plasma 17-OHP profiles obtained in untreated children with congenital adrenal hyperplasia. Extremely high morning and relatively low evening serum 17-OHP values were documented in two children aged 3 and 4 years old before treatment, and in three other children studied after treatment was stopped. ${ }^{2021}$
Despite wide fluctuations in 17-OHP concentrations none of the values in newborns were within the normal range. In contrast, blood spot 17-OHP values obtained in the evening from some infants and children older than 3 months were near the upper reference limit of the assay method. The results indicate that samples for the diagnosis of congenital adrenal hyperplasia in children older than 3 months should be collected in the morning.

The study of a specific group of patients with raised endogenous adrenocorticotrophic hormone concentrations has provided information on an age related development in the diurnal rhythm of pituitary-adrenal activity.

I thank Dr T Fehér for the antiserum used in the radioimmunoassay; Dr I Dóber, Dr S Hervei, Dr I Ilyés, Dr L Kelemen, Dr Zs Kékesi, Dr K Kürti, Dr K Kánya, and Dr L Ságodi for their help in obtaining specimens from some of the patients; Mrs Gudrun Kirchknopf for her excellent technical assistance; and Dr I A Hughes of the Welsh National School of Medicine, Cardiff, for his valuable suggestions for the preparation of this manuscript.

\section{References}

${ }^{1}$ Krieger DT, Allen W, Rizzo F, Krieger HP. Characterization of the normal temporal pattern of plasma corticosteroid levels. J Clin Endocrinol Metab 1971;32:266-84.

2 Price DA, Close GC, Fielding BA. Age of appearance of circadian rhythm in salivary cortisol values in infancy. Arch Dis Child 1983;58:454-6.

${ }^{3}$ Onishi S, Miyazama G, Nishimura Y, et al. Postnatal development of circadian rhythm in serum cortisol levels in children. Pediatrics 1983;72:399-404.

${ }^{4}$ Franks RC. Diurnal variation of plasma 17-hydroxycorticosteroids in children. J Clin Endocrinol Metab 1967;27: 75-8.

5 Fukushima DK, Finkelstein JW, Yoshida K, Boyar RM, Hellman L. Pituitary-adrenal activity in untreated congenital adrenal hyperplasia. J Clin Endocrinol Metab 1975;40:1-12.

6 Meyer WJ, Gutai JP, Keenan BS, et al. A chronobiological approach to the treatment of congenital adrenal hyperplasia. In: Lee PA, Plotnick LP, Kowarski AA, Migeon CJ, eds. Congenital adrenal hyperplasia. Baltimore: University Park Press, 1977:203-15.

${ }^{7}$ Nieschlag E, Wenner H, Breu H, Wickings EJ, Schellong G. Adrenogenitales syndrom. Therapeutische einstellung anhand des tagesprofils des 17-hydroxyprogesterons in serum. Dtsch Med Wochenschr 1980;105:600-3.

${ }^{8}$ Smith R, Donald RA, Espiner EA, et al. The effect of different treatment regimens on hormonal profiles in congenital adrenal hyperplasia. J Clin Endocrinol Metab 1980;51:230-6.

9 Bacon GE, Spencer ML, Kelch RP. Effects of cortisol treatment on hormonal relationships in congenital adrenal hyperplasia. Clin Endocrinol 1977;6:113-26.

10 Zipf WB, Bacon GE, Kelch RP. Hormonal and clinical responses to prednisone treatment in adolescents with congenital adrenal hyperplasia. Horm Res 1980;12:206-17.

1 Sólyom J, Hervei S, Marossy P, et al. 'Dot-17-alphahydroxyprogesterone' radioimmunoassay for identification of congenital adrenal hyperplasia in young infants. Acta Paediatr Scand 1981;70:913-7.

12 Sólyom J. Blood-spot 17-alpha-hydroxyprogesterone radioimmunoassay in the follow-up of congenital adrenal hyperplasia. Clin Endocrinol 1981:14:547-53. 
13 Sólyom J. Analysis of steroid hormones in biological samples dried on filter paper. In: Görög S, ed. Advances in steroid analysis. Budapest: Publishing House of the Hungarian Academy of Science, 1982:201-5.

14 Pang S, Hotchkiss J, Drash AL, Levine LS, New MI. Microfilter paper method for 17-alpha-hydroxyprogesterone radioimmunoassay-its application for rapid screening for congenital adrenal hyperplasia. J Clin Endocrinol Metab 1977;45:1003-8.

15 Hubl W, Fehér T, Rohde W, et al. Enzyme immunoassay of 17-hydroxyprogesterone in plasma, microfilter paper blood and saliva of newborns, children and patients with congenital adrenal hyperplasia. Endokrinologie 1982;79:165-72.

16 Pang S, Murphy W, Levine LS, et al. A pilot newborn screening for congenital adrenal hyperplasia in Alaska. J Clin Endocrinol Metab 1982;55:413-20.

17 Cacciari E, Balsamo A, Cassio A, et al. Neonatal screening for congenital adrenal hyperplasia. Arch Dis Child 1983;58:803-6.

${ }^{18}$ Hughes IA, Winter JSD. The application of a serum
$17 \mathrm{OH}$-progesterone radioimmunoassay to diagnosis and management of congenital adrenal hyperplasia. $J$ Pediatr 1976;88:766-73.

19 Murphy JF, Joyce BG, Dyas J, Hughes IA. Plasma 17 hydroxyprogesterone concentrations in ill newborn infants. Arch Dis Child 1983;58:532-4.

20 Atherden SM, Barnes ND, Grant DB. Circadian variation in plasma 17-hydroxyprogesterone in patients with congenital adrenal hyperplasia. Arch Dis Child 1972;47:602-4.

${ }^{21}$ Frisch H, Parth K, Schober E, Swoboda W. Circadian patterns of plasma cortisol, 17-hydroxyprogesterone, and testosterone in congenital adrenal hyperplasia. Arch Dis Child 1981;56:208-13.

Correspondence to J Sólyom, 2nd Department of Paediatrics, Semmelweis Medical University, Tüzoltó u 7, 1094 Budapest, Hungary.

Received 5 April 1984 